\title{
The Effects of Different Sealing Techniques for Anodic Film of Al-12.7Si-0.7Mg Alloys
}

\author{
Yan Shang ${ }^{1,2}$, Linshan Wang ${ }^{2, *}$, Zhaoyue Liu ${ }^{2}$, Dun Niü ${ }^{2}$, Yuhong Wang ${ }^{2}$, Changsheng Liu ${ }^{1, *}$ \\ ${ }^{1}$ Key Laboratory of Anisotropy and Texture of Materials, Ministry of Education, Northeastern \\ University, Shenyang 110819, P. R. China. \\ ${ }^{2}$ College of Science, Northeastern University, Shenyang 110819, P. R. China. \\ *E-mail: 1swang@mail.neu.edu.cn, csliu@mail.neu.edu.cn
}

doi: $10.20964 / 2016.06 .85$

Received: 6 March 2016 / Accepted: 19 March 2016 / Published: 4 May 2016

\begin{abstract}
Al-12.7Si-0.7Mg is a novel kind of high silicon aluminum alloy and urgently in need of surface treatment technologies. Optimal processing parameters of stearic acid sealing treatment were investigated by evaluating the weight loss of anodic film. The anodic films were sealed by other four sealing methods of boiling water sealing, nickel acetate sealing, chromate sealing and cold nickel fluoride sealing in order to compare with stearic acid sealing. Surface morphology of anodic oxide films after sealing treatment showed that stearic acid sealing specimens were smooth, uniform and compact. The results of potentiodynamic polarization, phosphorus-chromium acid oxide method and alkaline etching test indicated that stearic acid sealing was more highly effective and environmentally friendly and exhibited excellent corrosion resistance.
\end{abstract}

Keywords: Al-12.7Si-0.7Mg alloy; anodizing; stearic acid; sealing; corrosion resistance

\section{FULL TEXT}

(C) 2016 The Authors. Published by ESG (www.electrochemsci.org). This article is an open access article distributed under the terms and conditions of the Creative Commons Attribution license (http://creativecommons.org/licenses/by/4.0/). 